\title{
High-dose rifaximin treatment alleviates global symptoms of irritable bowel syndrome
}

This article was published in the following Dove Press journal:

Clinical and Experimental Gastroenterology

16 April 201 I

Number of times this article has been viewed

John Jolley

Department of Medicine, University of California, San Francisco, CA, USA
Correspondence: John Jolley

7II D Street, Suite 108, San Rafael,

CA 9490I, USA

Tel +I 4152573030

Fax + I 4I5 2573040

Email baycro@aol.com
Background: To evaluate the efficacy of rifaximin for reduction of gastrointestinal symptoms in patients with irritable bowel syndrome (IBS).

Methods: Medical records were identified for consecutive patients diagnosed with IBS according to Rome III criteria, who had abnormal lactulose breath test results and had received rifaximin $1200 \mathrm{mg} /$ day for 10 days. The efficacy of rifaximin for reducing gastrointestinal symptoms and for eradicating small intestinal bacterial overgrowth was ascertained in these patients. In addition, these endpoints were examined in patients who were initially unresponsive to rifaximin $1200 \mathrm{mg} /$ day and received subsequent rifaximin $2400 \mathrm{mg} /$ day.

Results: Patients who received rifaximin $1200 \mathrm{mg} /$ day $(\mathrm{n}=162)$ experienced a mean improvement of $52 \%$ in global IBS symptoms at the end of rifaximin treatment. Similarly, initially unresponsive patients who received additional rifaximin $2400 \mathrm{mg} /$ day $(\mathrm{n}=81)$ experienced a $53 \%$ mean improvement in global IBS symptoms. Forty-nine percent of patients who received initial rifaximin and $47 \%$ of patients who received high-dose rifaximin achieved $\geq 50 \%$ global symptom improvement during at least one follow-up visit. Normalization of lactulose breath test results was only apparent in some patients who received high-dose rifaximin. Rifaximin was well tolerated.

Conclusion: Rifaximin $1200 \mathrm{mg}$ /day for 10 days reduced gastrointestinal symptoms in patients with IBS. Patients with incomplete symptom resolution may respond to increased doses of rifaximin.

Keywords: small intestinal bacterial overgrowth, irritable bowel syndrome, rifaximin, lactulose breath test

\section{Introduction}

Irritable bowel syndrome (IBS) is a disease of altered gastrointestinal motility, in which patients often experience predominant symptoms of constipation or diarrhea. ${ }^{1}$ It is prevalent in the US, affecting up to $20 \%$ of individuals, ${ }^{2}$ but the etiology of the disease remains elusive. ${ }^{3}$ Several psychological and organic causes have been postulated to contribute to the development of IBS, including psychosocial factors (depression, anxiety), ${ }^{3,4}$ alterations in gastrointestinal neurotransmission (serotonin levels), ${ }^{3,4}$ and small intestinal bacterial overgrowth. ${ }^{3-6}$ Small intestinal bacterial overgrowth, in particular, has come into the spotlight because of data suggesting that patients with IBS may have altered intestinal microflora, with decreased concentrations of coliforms, lactobacilli, and bifidobacteria, as well as increased numbers of anaerobes, Escherichia coli, and bacteroides. . $^{3,8}$ These recent advances in understanding the etiology of IBS have provided a new avenue for potential therapies, such as nonsystemic antibiotics, that may target disease pathology. ${ }^{9-12}$ 
Typical treatments for IBS, such as antispasmodics, antidepressants, $\mathrm{C}-2$ chloride channel activators, and 5- $\mathrm{HT}_{3}$ receptor antagonists, focus on symptom relief, ${ }^{1,13}$ and do not address the underlying cause of the disorder. Current guidelines from the American College of Gastroenterology provide a strong recommendation (ie, 1B) for antidepressants, C-2 chloride channel activators for females with constipationpredominant IBS, and 5- $\mathrm{HT}_{3}$ receptor antagonists for females with severe diarrhea-predominant IBS. However, limited availability, tolerability, and efficacy for all IBS subtypes emphasize the necessity for other treatment options. ${ }^{14}$ The American College of Gastroenterology guidelines have strongly recommended the use of nonsystemic antibiotics, such as rifaximin, for IBS based on moderate evidence. Rifaximin is approved for treatment of travelers' diarrhea and the reduction of hepatic encephalopathy recurrence, and has been shown to alleviate symptoms in patients with IBS. ${ }^{11,15-19}$ Increased dosage of rifaximin has been shown to normalize glucose breath test results in patients with small intestinal bacterial overgrowth, ${ }^{20}$ and given the connection between small intestinal bacterial overgrowth and IBS, treatment with a higher dose of rifaximin may provide symptom relief in patients with recurrent IBS.

This retrospective chart review examined the efficacy of rifaximin $1200 \mathrm{mg} /$ day in alleviating global symptoms in patients with IBS and the ability of high-dose rifaximin ( $2400 \mathrm{mg} /$ day) to improve IBS symptoms in patients initially unresponsive to rifaximin. The study also evaluated the ability of rifaximin to eradicate small intestinal bacterial overgrowth in patients with IBS.

\section{Materials and methods Patient population}

Medical records from a single center were identified for consecutive patients diagnosed with IBS according to Rome III criteria, who were aged $\geq 16$ years, had an abnormal lactulose breath test result between October 2006 and July 2007, and had received rifaximin $1200 \mathrm{mg}$ /day (Xifaxan ${ }^{\circledR}$, Salix Pharmaceuticals, Inc, Morrisville, NC) for 10 days at any time. Before the lactulose breath test, patients were given dietary restrictions (eg, no beans or heavy meat 24 hours before testing), could not chew gum or participate in strenuous physical exercise nine hours before testing, and were not allowed to smoke two hours before the lactulose breath test. For this test, patients ingested $10 \mathrm{~g}$ of lactulose. An abnormal lactulose breath test result was defined as a $\geq 10 \mathrm{ppm}$ increase in baseline $\mathrm{H}_{2}$ or $\mathrm{CH}_{4}$ excretion within 90 minutes. Patients were excluded if they had used an oral antibiotic within three weeks before rifaximin treatment or if they had a history of inflammatory bowel disease, bowel resection surgery, or a colonic mucosal biopsy compatible with inflammatory bowel disease or microscopic colitis. Furthermore, patients were excluded if they displayed any of the following at baseline: a positive sprue screen (antigliadin antibody IgA, tissue transglutaminase IgA, total IgA), a positive stool antigen test for Giardia or Cryptosporidium, positivity for fecal leukocytes, positivity for Clostridium difficile toxins A or B, or levels of C-reactive protein $>8 \mathrm{mg} / \mathrm{L}$.

\section{Data extraction}

Data for baseline IBS symptoms, rifaximin dosing regimen, concomitant medication usage, and IBS symptom improvement were extracted from patient charts. Only charts of patients who received initial treatment with rifaximin $1200 \mathrm{mg}$ /day and were retreated with rifaximin $2400 \mathrm{mg}$ /day if symptoms continued were included in the analyses. Collection of lactulose breath test results obtained initially and 4-14 days following rifaximin completion was also performed. Note was made of hydrogen-positive, methanepositive, hydrogen- and methane-positive, flatline, negative, distal-positive, high-baseline, and inconclusive lactulose breath test results.

Response to initial rifaximin (1200 mg/day) and highdose rifaximin (2400 mg/day) was based on global symptom improvement from baseline and was assessed by the patients using a visualized scale ranging from $0 \%$ to $100 \%$. Patients were also asked to rate the percentage improvement from baseline of specific IBS symptoms (abdominal pain or discomfort, bloating, constipation, diarrhea, gas, or other symptoms) at follow-up visits after both treatment regimens. Symptom improvement was categorized as complete improvement ( $\geq 91 \%$ ), partial improvement (1\%-90\%), or no improvement $(0 \%)$. Diagnosis of IBS was noted to be constipation-predominant IBS, diarrhea-predominant IBS, or mixed-symptom IBS when reported. Completion of rifaximin therapy was ascertained from all charts, and when withdrawal from the study was noted, the reason was recorded as adverse event related or not related to rifaximin. Specific treatment-related adverse events were also collected from all charts.

\section{Data analysis}

The average percent global improvement of baseline IBS symptoms at the end of rifaximin therapy (both initial rifaximin $1200 \mathrm{mg} /$ day and retreatment with rifaximin $2400 \mathrm{mg}$ /day) was analyzed without regard to lactulose breath 
test measurements. Percentages of patients with improvement in global and IBS-related symptoms (eg, abdominal pain and discomfort, bloating, constipation, diarrhea, and gas) were recorded for each patient at all visits. The percentage of patients who achieved $\geq 50 \%$ global IBS symptom improvement during at least one follow-up visit ( $\geq 50 \%$ best global improvement) was also ascertained. Normalization of lactulose breath test results within 4-14 days after rifaximin cessation and the percentage of patients with normal lactulose breath test results and global symptom improvement at the end of rifaximin therapy were evaluated. Subanalyses were also conducted for improvement of global and specific IBS symptoms and lactulose breath test results by IBS subclassification (ie, diarrhea-predominant IBS, constipationpredominant IBS, or mixed-symptom IBS).

\section{Results}

\section{Patient population}

A total of 236 patient charts were reviewed, and 162 were selected for further analysis after application of inclusion/ exclusion parameters. All 162 patients received initial treatment with rifaximin $1200 \mathrm{mg}$ /day for 10 days. Among these individuals, 45 (28\%) were classified as having diarrheapredominant IBS, 33 (20\%) were classified as having constipation-predominant IBS, and 24 (15\%) were classified as having mixed-symptom IBS. Lactulose breath test results indicated that 91 patients $(56 \%)$ were hydrogen positive, $32(20 \%)$ were methane positive, and $9(6 \%)$ were positive for both hydrogen and methane (Table 1). In addition, 81 of the initial 162 patients $(50 \%)$ received subsequent treatment with rifaximin $2400 \mathrm{mg} /$ day for 10 days because of incomplete symptom resolution (Table 1).

\section{Response to initial treatment with rifaximin}

Patients who received rifaximin $1200 \mathrm{mg} /$ day experienced a mean improvement of $52 \%$ in global IBS symptoms at the end of rifaximin treatment (Figure 1). In addition, after initial rifaximin $1200 \mathrm{mg}$ /day for 10 days, $49 \%$ of patients (79 of 162 ) reported $\geq 50 \%$ best global improvement in IBS symptoms (Figure 2). This improvement was IBS-subtype specific, with $56 \%$ of patients ( 25 of 45 ) diagnosed with diarrhea-predominant IBS experiencing $\geq 50 \%$ best global improvement compared with $45 \%$ of individuals (15 of 33) with constipation-predominant IBS (Figure 3). Complete symptom relief ( $\geq 91 \%$ improvement) was achieved in 19 of 162 patients $(12 \%)$ and was not dependent on IBS subcategory (Table 2). Eight percent of patients (13 of 162)
Table I Patient demographics and characteristics

\begin{tabular}{|c|c|c|}
\hline Parameter & $\begin{array}{l}\text { Rifaximin } \\
\text { I } 200 \mathrm{mg} / \text { day } \\
(\mathrm{n}=\mid 62)\end{array}$ & $\begin{array}{l}\text { Rifaximin } \\
2400 \mathrm{mg} / \text { day } \\
(\mathrm{n}=8 \mathrm{I})\end{array}$ \\
\hline Mean age (range), years & $58(|7-9|)$ & $60(|7-9|)$ \\
\hline Male:Female & $37: 125$ & $22: 59$ \\
\hline Race, n (\%) & $43(27)$ & $25(3 \mathrm{I})$ \\
\hline White & $2(I)$ & $I(I)$ \\
\hline Black & $2(1)$ & $0(0)$ \\
\hline Asian & $4(2)$ & $2(2)$ \\
\hline Hispanic & $2(1)$ & $2(2)$ \\
\hline Other & $109(67)$ & $51(63)$ \\
\hline Not reported & $43(27)$ & $25(31)$ \\
\hline $\begin{array}{l}\text { Mean duration of IBS } \\
\text { (range), mo }\end{array}$ & $113.1(6-480)$ & $128.4(6-480)$ \\
\hline \multicolumn{3}{|l|}{ Disease subclass, $n(\%)$} \\
\hline IBS-D & $45(28)$ & $24(30)$ \\
\hline IBS-C & $33(20)$ & $16(20)$ \\
\hline IBS-M & $24(15)$ & $11(14)$ \\
\hline Not reported & $60(37)$ & $30(37)$ \\
\hline \multicolumn{3}{|c|}{ Lactulose breath test results, $\mathrm{n}(\%)^{\mathrm{a}}$} \\
\hline Distal positive ${ }^{\mathrm{b}}$ & $17(10)$ & $10(12)$ \\
\hline Hydrogen & $91(56)$ & $44(54)$ \\
\hline Methane & $32(20)$ & $18(22)$ \\
\hline Hydrogen and methane & $9(6)$ & $4(5)$ \\
\hline High baseline $^{c}$ & $23(14)$ & $10(12)$ \\
\hline Flatline $^{d}$ & $27(17)$ & $15(19)$ \\
\hline Negative $^{e}$ & $4(2)$ & $I(I)$ \\
\hline Inconclusive & $34(21)$ & $18(22)$ \\
\hline
\end{tabular}

Notes: apatients positive for hydrogen, methane, or both gases may have exhibited a high baseline or lacked a biphasic excretion pattern (distal positive); ${ }^{b}$ patients who did not exhibit a biphasic pattern of gas excretion; 'patients with $\geq 20$ ppm before lactulose ingestion; ${ }^{\mathrm{d}}$ patients with a $<10 \mathrm{ppm}$ increase in gas excretion within 120 minutes of lactulose ingestion; ${ }^{e}$ patients with a $<10$ ppm increase in gas excretion within 90 minutes of lactulose ingestion.

Abbreviations: IBS, irritable bowel syndrome; IBS-D, diarrhea-predominant irritable bowel syndrome; IBS-C, constipation-predominant irritable bowel syndrome; IBS-M, mixed-symptom irritable bowel syndrome.

achieved partial relief (1\%-90\%) of overall symptoms, with individuals having constipation-predominant IBS receiving the greatest benefit. The predominant symptom (diarrhea or constipation) was completely relieved in $13 \%$ of patients with diarrhea-predominant IBS and in $12 \%$ of patients with constipation-predominant IBS (Table 2). Similarly, 17\% of patients with mixed-symptom IBS displayed complete relief of diarrhea, and $13 \%$ had complete relief of constipation (Table 2). Only $2 \%$ of patients treated with initial rifaximin displayed a normal lactulose breath test result post-treatment.

\section{Response to further treatment with high-dose rifaximin}

Patients who did not respond to initial rifaximin were administered additional rifaximin (2400 $\mathrm{mg}$ /day for 10 days, $\mathrm{n}=81)$. Patients who received high-dose rifaximin (2400 mg/day) 


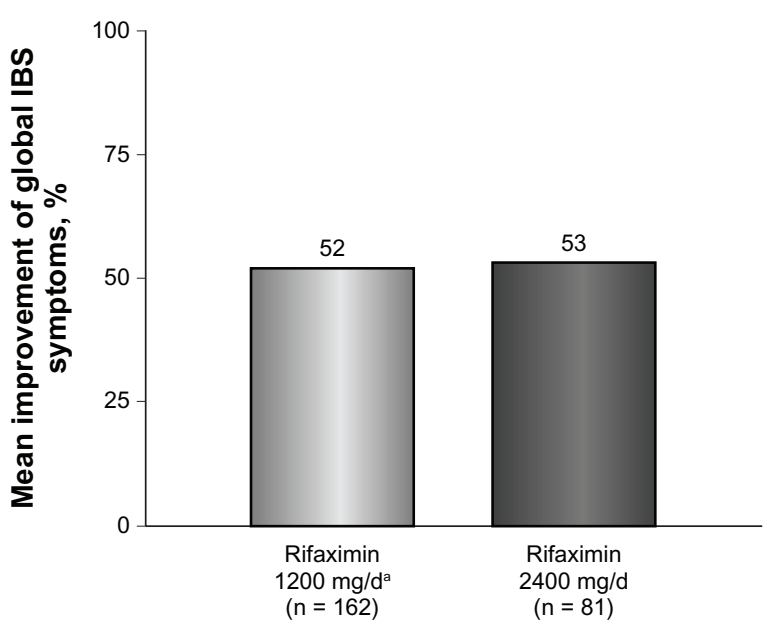

Figure I Mean percent improvement in global IBS symptoms at the end of rifaximin treatment. The mean percent improvement in global IBS symptoms was similar in patients with IBS who received rifaximin $1200 \mathrm{mg} /$ day for 10 days $(52 \%)$ and in patients with IBS who received subsequent high-dose rifaximin $(2400 \mathrm{mg} /$ day $)$ for 10 days $(53 \%)$.

Note: ancludes patients who received additional high-dose rifaximin therapy.

Abbreviation: IBS, irritable bowel syndrome.

experienced a mean improvement in global IBS symptoms of $53 \%$ at the termination of rifaximin therapy, which was similar to the percent improvement experienced in patients responsive to rifaximin $1200 \mathrm{mg}$ /day (Figure 1). In addition, treatment with high-dose rifaximin elicited $\geq 50 \%$ best global symptom improvement in patients initially lacking a response to lower-dose rifaximin. Among the 81 patients receiving further rifaximin treatment, 38 (47\%) exhibited $\geq 50 \%$ best improvement in overall global symptoms, which was similar to that reported during initial rifaximin $1200 \mathrm{mg}$ /day for 10 days (Figure 2). Patients with mixed-symptom IBS received

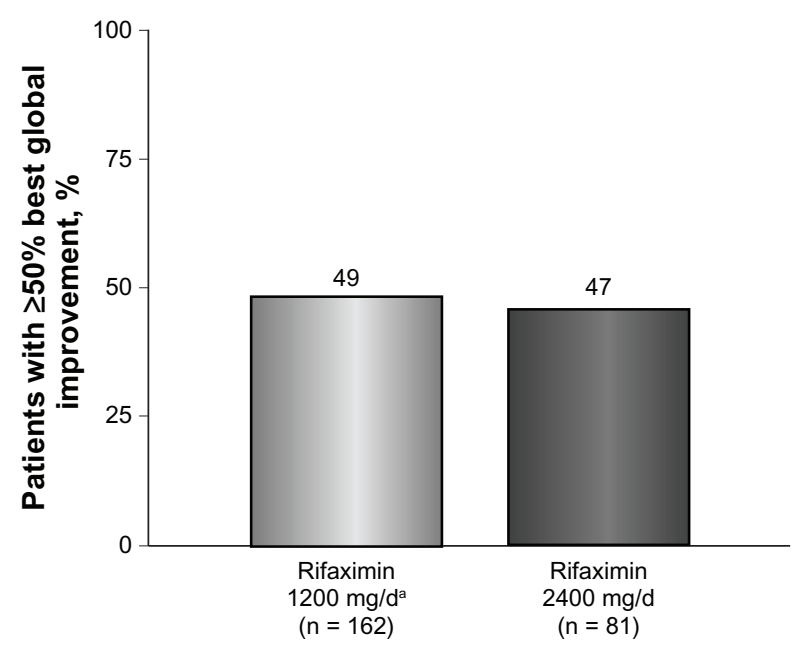

Figure 2 Percentage of patients obtaining $\geq 50 \%$ best global improvement following rifaximin treatment. Global symptoms improved in 79 of 162 patients $(49 \%)$ who received rifaximin $1200 \mathrm{mg} /$ day for 10 days compared with 38 of 81 patients (47\%) who received high-dose rifaximin $(2400 \mathrm{mg} /$ day) for 10 days.

Note: alncludes patients who received additional high-dose rifaximin therapy.

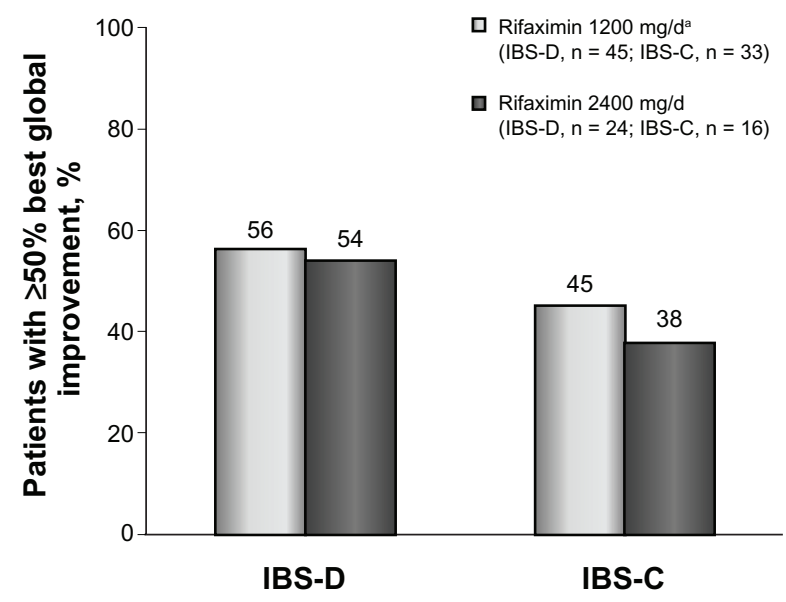

Figure 3 Percentage of patients with IBS-D or IBS-C who obtained $\geq 50 \%$ best global improvement following rifaximin treatment. Rifaximin effectively reduced irritable bowel syndrome symptoms in patients with either subtype. Interestingly, rifaximin $2400 \mathrm{mg} /$ day elicited $\geq 50 \%$ symptom improvement in patients with either subtype who initially lacked response to rifaximin $1200 \mathrm{mg} /$ day.

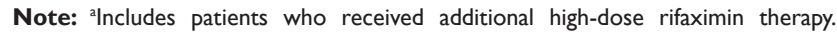
Abbreviations: IBS-C, constipation-predominant irritable bowel syndrome; IBS-D, diarrhea-predominant irritable bowel syndrome.

the greatest benefit from high-dose rifaximin, with six of 11 patients (55\%) reporting best global improvement $\geq 50 \%$. More patients with diarrhea-predominant IBS experienced best global improvement $\geq 50 \%$ compared with individuals with constipation-predominant IBS, with 13 of 24 patients with diarrhea-predominant IBS (54\%) displaying best global improvement $\geq 50 \%$ compared with only six of 16 patients with constipation-predominant IBS (38\%, Figure 3). Complete symptom reduction ( $\geq 91 \%$ ) was reported in nine of 81 patients (11\%) and was not subtype dependent. However, complete reduction of the predominant symptom (diarrhea or constipation) was greater in patients with diarrhea-predominant IBS $(17 \%)$ than in patients experiencing constipationpredominant IBS $(6 \%$, Table 2$)$. Interestingly, patients with mixed-symptom IBS reported larger remission of diarrheal symptoms (18\%) than constipation symptoms ( $0 \%$, Table 2$)$. Partial relief (1\%-90\%) of global IBS symptoms was achieved in $10 \%$ of initially unresponsive patients after high-dose rifaximin, and of these, $8 \%, 13 \%$, and $18 \%$ of patients with diarrhea-predominant IBS, constipation-predominant IBS, and mixed-symptom IBS, respectively, reported partial relief. In contrast with initial rifaximin therapy, high-dose rifaximin successfully normalized lactulose breath test results in nine of 81 patients $(11 \%)$.

\section{Adverse events}

Of the 162 patients receiving initial rifaximin $1200 \mathrm{mg} /$ day for 10 days, only 13 (8\%) reported adverse events. Similarly, only five of 81 patients $(6 \%)$ administered additional 
Table 2 Complete relief of IBS symptoms following rifaximin treatment

\begin{tabular}{|c|c|c|}
\hline & \multicolumn{2}{|l|}{ Patients, n (\%) } \\
\hline & $\begin{array}{l}\text { Rifaximin } \\
\text { I } 200 \mathrm{mg} / \text { day } \\
(\mathrm{n}=162)\end{array}$ & $\begin{array}{l}\text { Rifaximin } \\
2400 \mathrm{mg} / \text { day } \\
(\mathrm{n}=8 \mathrm{I})\end{array}$ \\
\hline \multicolumn{3}{|l|}{ All IBS } \\
\hline Global symptoms & $19(12)$ & $9(11)$ \\
\hline Abdominal pain & $15(9)$ & $2(2)$ \\
\hline Bloating & $17(10)$ & $5(6)$ \\
\hline Constipation & $9(6)$ & $4(5)$ \\
\hline Diarrhea & $15(9)$ & $8(10)$ \\
\hline Gas & $16(10)$ & $5(6)$ \\
\hline \multicolumn{3}{|l|}{ IBS-Da } \\
\hline Global symptoms & $5(\mathrm{II})$ & $3(13)$ \\
\hline Abdominal pain & $5(\mathrm{II})$ & $0(0)$ \\
\hline Bloating & $6(13)$ & I (4) \\
\hline Constipation & $0(0)$ & $0(0)$ \\
\hline Diarrhea & $6(13)$ & $4(17)$ \\
\hline Gas & $4(9)$ & I (4) \\
\hline \multicolumn{3}{|l|}{ IBS-C ${ }^{a}$} \\
\hline Global symptoms & $4(12)$ & I (6) \\
\hline Abdominal pain & $3(9)$ & $0(0)$ \\
\hline Bloating & $2(6)$ & $0(0)$ \\
\hline Constipation & $4(12)$ & I (6) \\
\hline Diarrhea & I (3) & $0(0)$ \\
\hline Gas & $4(12)$ & $I(6)$ \\
\hline \multicolumn{3}{|l|}{ IBS-Ma } \\
\hline Global symptoms & $4(17)$ & $2(18)$ \\
\hline Abdominal pain & $3(13)$ & $0(0)$ \\
\hline Bloating & $4(17)$ & I (9) \\
\hline Constipation & $3(13)$ & $0(0)$ \\
\hline Diarrhea & $4(17)$ & $2(18)$ \\
\hline Gas & $3(13)$ & I (9) \\
\hline
\end{tabular}

Note: aPatients not subclassified as IBS-D, IBS-C, or IBS-M were not included in this analysis.

Abbreviations: IBS, irritable bowel syndrome; IBS-D, diarrhea-predominant irritable bowel syndrome; IBS-C, constipation-predominant irritable bowel syndrome; IBS-M, mixed-symptom irritable bowel syndrome.

rifaximin $2400 \mathrm{mg} /$ day for 10 days reported adverse events. Most of these adverse events occurred in the first 3-4 days of treatment and consisted of flu-like illness with diarrhea and nausea. These symptoms resolved by day 5 and were thought to be secondary to "bacterial kill".

\section{Discussion}

This retrospective chart review demonstrated that rifaximin $1200 \mathrm{mg} /$ day for 10 days improved global and IBS-related symptoms. This finding is consistent with data from two Phase III clinical trials showing that rifaximin $550 \mathrm{mg}$ three times daily for 14 days adequately relieved global IBS symptoms and IBS-related bloating for at least two of the first four weeks of treatment, and improved daily assessments of IBS symptoms, bloating, abdominal pain, and stool consistency compared with placebo. ${ }^{19}$ However, the initial dose of rifaximin examined in the current work (ie, rifaximin $1200 \mathrm{mg} /$ day) was lower than that used in the Phase III trials (ie, $1650 \mathrm{mg}$ / day). Several prospective studies have shown that rifaximin $800 \mathrm{mg}$ /day or $1200 \mathrm{mg}$ /day for 10 days improved IBS symptoms and eradicated small intestinal bacterial overgrowth, ${ }^{15,16}$ but because of differences in study design and inclusion criteria, it is not possible to compare these studies with the Phase III trials. Thus, the optimum dose of rifaximin for IBS remains unknown. Results from the current study, however, imply that patients who are initially unresponsive to rifaximin therapy may benefit from an escalation in rifaximin dose.

Few studies have examined the efficacy of rifaximin for specific subpopulations of IBS (ie, diarrhea-predominant IBS, constipation-predominant IBS, and mixed-symptom IBS). Phase III clinical trials of rifaximin have limited patient inclusion to "non-constipation IBS" (ie, diarrheapredominant IBS or mixed-symptom IBS); ${ }^{19}$ therefore, possible differences in the efficacy of rifaximin among patients with different IBS subtypes remains unknown. In the current study, rifaximin was effective in all subtypes of IBS. Although a greater percentage of patients with diarrhea-predominant IBS had an initial response, patients with mixed-symptom IBS were more likely to respond to high-dose rifaximin. In addition, symptoms of diarrhea and constipation were equally relieved in patients with mixed-symptom IBS.

Rifaximin is a generally well-tolerated nonsystemic antibiotic that elicits few adverse events. Studies of rifaximin $800 \mathrm{mg} /$ day or $1200 \mathrm{mg} /$ day in patients with IBS demonstrated a similar occurrence of adverse events in the placebo and rifaximin groups. ${ }^{5,15,16}$ Although one might expect a larger number of adverse events with an increased medication dose, rifaximin $1600 \mathrm{mg} /$ day $^{19}$ or $2400 \mathrm{mg} /$ day is well tolerated.

These results are limited by the retrospective nature of the study and the lack of a placebo comparison group, but they provide evidence that rifaximin $1200 \mathrm{mg}$ /day may be a safe and beneficial alterative for patients with IBS and that studies designed to examine the efficacy of rifaximin in patients with diverse IBS symptoms are warranted. Furthermore, higher doses of rifaximin (ie, $2400 \mathrm{mg}$ /day) may increase the percentage of responsive patients.

\section{Disclosure}

The author has no competing interests or financial support for research to disclose.

\section{References}

1. Schoenfeld P. Efficacy of current drug therapies in irritable bowel syndrome: What works and does not work. Gastroenterol Clin North Am. 2005;34(2):319-335. 
2. Olden KW. Diagnosis of irritable bowel syndrome. Gastroenterology. 2002;122(6):1701-1704.

3. Barbara G, De Giorgio R, Stanghellini V, Cremon C, Salvioli B, Corinaldesi R. New pathophysiological mechanisms in irritable bowel syndrome. Aliment Pharmacol Ther. 2004;20 Suppl 2:1-9.

4. Talley NJ. Irritable bowel syndrome. Intern Med J. 2006;36(11): 724-728.

5. Majewski M, McCallum RW. Results of small intestinal bacterial overgrowth testing in irritable bowel syndrome patients: Clinical profiles and effects of antibiotic trial. Adv Med Sci. 2007;52:139-142.

6. Posserud I, Stotzer PO, Björnsson ES, Abrahamsson H, Simrén M. Small intestinal bacterial overgrowth in patients with irritable bowel syndrome. Gut. 2007;56(6):802-808.

7. Krogius-Kurikka L, Lyra A, Malinen E, et al. Microbial community analysis reveals high level phylogenetic alterations in the overall gastrointestinal microbiota of diarrhoea-predominant irritable bowel syndrome sufferers. BMC Gastroenterol. 2009;9:95.

8. Tana C, Umesaki Y, Imaoka A, Handa T, Kanazawa M, Fukudo S. Altered profiles of intestinal microbiota and organic acids may be the origin of symptoms in irritable bowel syndrome. Neurogastroenterol Motil. 2010;22(5):512-519.

9. Pimentel M, Chatterjee S, Chow EJ, Park S, Kong Y. Neomycin improves constipation-predominant irritable bowel syndrome in a fashion that is dependent on the presence of methane gas: Subanalysis of a double-blind randomized controlled study. Dig Dis Sci. 2006;51(8): 1297-1301.

10. Pimentel M, Chow EJ, Lin HC. Normalization of lactulose breath testing correlates with symptom improvement in irritable bowel syndrome: A double-blind, randomized, placebo-controlled study. Am J Gastroenterol. 2003;98(2):412-419.

11. Yang J, Lee HR, Low K, Chatterjee S, Pimentel M. Rifaximin versus other antibiotics in the primary treatment and retreatment of bacterial overgrowth in IBS. Dig Dis Sci. 2008;53(1):169-174.
12. Pimentel M, Chow EJ, Lin HC. Eradication of small intestinal bacterial overgrowth reduces symptoms of irritable bowel syndrome. Am J Gastroenterol. 2000;95(12):3503-3506.

13. Frissora CL, Cash BD. The role of antibiotics vs conventional pharmacotherapy in treating symptoms of irritable bowel syndrome. Aliment Pharmacol Ther. 2007;25(11):1271-1281.

14. Brandt LJ, Chey WD, Foxx-Orenstein AE, et al. An evidence-based position statement on the management of irritable bowel syndrome. Am J Gastroenterol. 2009;104 Suppl 1:S1-S35.

15. Pimentel M, Park S, Mirocha J, Kane SV, Kong Y. The effect of a nonabsorbed oral antibiotic (rifaximin) on the symptoms of the irritable bowel syndrome. Ann Intern Med. 2006;145(8):557-563.

16. Sharara AI, Aoun E, Abdul-Baki H, Mounzer R, Sidani S, ElHajj I. A randomized double-blind placebo-controlled trial of rifaximin in patients with abdominal bloating and flatulence. $\mathrm{Am} \mathrm{J}$ Gastroenterol. 2006;101(2):326-333.

17. Peralta S, Cottone C, Doveri T, Almasio PL, Craxi A. Small intestine bacterial overgrowth and irritable bowel syndrome-related symptoms: Experience with rifaximin. World J Gastroenterol. 2009;15(21): $2628-2631$.

18. Low K, Hwang L, Hua J, Zhu A, Morales W, Pimentel M. A combination of rifaximin and neomycin is most effective in treating irritable bowel syndrome patients with methane on lactulose breath test. J Clin Gastroenterol. 2010;44(8):547-550.

19. Pimentel M, Lembo A, Chey WD, et al; for the TARGET Study Group. Rifaximin therapy for patients with irritable bowel syndrome without constipation. N Engl J Med. 2011;364(1):22-32.

20. Scarpellini E, Gabrielli M, Lauritano CE, et al. High dosage rifaximin for the treatment of small intestinal bacterial overgrowth. Aliment Pharmacol Ther. 2007;25(7):781-786.
Clinical and Experimental Gastroenterology

\section{Publish your work in this journal}

Clinical and Experimental Gastroenterology is an international, peerreviewed, open access journal, publishing all aspects of gastroenterology in the clinic and laboratory, including: Pathology, pathophysiology of gastrointestinal disease; Investigation and treatment of gastointestinal disease; Pharmacology of drugs used in the alimentary tract;

\section{Dovepress}

Immunology/genetics/genomics related to gastrointestinal disease. This journal is indexed on CAS. The manuscript management system is completely online and includes a very quick and fair peer-review system. Visit http://www.dovepress.com/testimonials.php to read real quotes from published authors. 